International Journal of Hiology, Pharmacy and Allied Seiences (IJBPAS) 'A Bridge Betuen Caboratory and Qnendo'

WWW.ijbpas.com

\title{
EFFICACY OF MINIPLATES IN TRAUMA MANAGEMENT
}

\section{SHARON KEZIAH.V ${ }^{1}$, HEMAVATHY O $\mathbf{R}^{2^{*}}$ AND PRADEEP KUMAR. $\mathbf{R}^{3}$}

1: Saveetha Dental College and Hospitals, Saveetha Institute of Medical and Technical Sciences, Saveetha University, Chennai 600077

2: Associate Professor, Department of Oral and Maxillofacial Surgery, Saveetha Dental College and Hospitals, Saveetha Institute of Medical and Technical Sciences, Saveetha University,

Chennai 600077

3: Professor and Head, Department of Public Health Dentistry, Saveetha Dental College and Hospitals, Saveetha Institute of Medical and Technical Sciences, Saveetha University, Chennai 600077

*Corresponding Author: E Mail: Dr. Hemavathy O R: hemavathy.sdc@saveetha.com Received 19 ${ }^{\text {th }}$ March 2021; Revised 25 ${ }^{\text {th }}$ April. 2021; Accepted 20 ${ }^{\text {th }}$ May 2021; Available online $1^{\text {st }}$ Aug. 2021 https://doi.org/10.31032/IJBPAS/2021/10.8.1072

ABSTRACT

Traumatic injuries can vary from minor isolated wounds to severe fractures that become difficult to manage in emergency medicine. Recently designed systems in trauma management are the miniplate system. The miniplates used in trauma management have turned out to be of great advantage in terms of stability and success. This study evaluates the efficacy of miniplates as treatment modality in fracture of maxillofacial region. This was a cross sectional study analyzing 76 patients who reported to the Department of Oral and Maxillofacial Surgery, Saveetha Dental College, Chennai with maxillofacial trauma from June 2019-March 2020. The data was analyzed and the results were recorded. Out of the 76 subjects who have undergone trauma management, $81.3 \%$. showed satisfactory healing in the immediate review one day after surgery and $18.67 \%$ with further review after 1 week. Road traffic accidents (66.67\%) were the most common etiological cause reported. Majority $(80 \%)$ and only $4 \%$ with overall complications. of the patients showed no postoperative complications. Among the target population, the majority of the patients were male (85.5\%) and female (14.5\%). This study also revealed that titanium miniplate (53.3\%) was the most frequently used material followed by stainless steel miniplates $(46.7 \%)$. 
The use of miniplates in trauma management during emergency situations was found to have a high rate of success and reliability. However due to certain limitations in this study, further studies with large sample size is required.

\section{Keyword: Miniplates, trauma management, mandibular fractures, stainless steel}

\section{INTRODUCTION}

Trauma specifically in the maxillofacial region is common in children as well as adolescents. Fracture can be defined as 'breach in the continuity of bone' [1]. Mandible is the second most common facial bone fracture $[2,3]$. Association of maxillofacial fractures with significant morbidity, facial disfigurement and loss of motor and sensory functions along with post operative complications has imposed a greater challenge for healthcare professionals

\section{$[2,4,5]$.}

The etiology varies among different populations, countries, regions, socioeconomic status [6], culture and lifestyle. According to various studies globally road traffic accidents is the most common cause in a developing country like India [2]. One such example of such differing epidemiology include the higher incidence of sports-related facial injuries in regions with higher participation of heavy contact sports and the regions with high prevalence of road traffic accidents [2, 7].

Many effective treatment methods and devices have been used in trauma management including facial bandage, extra oral fixation apparatus, intraoral cyclic arch bars $[\mathbf{1}, \mathbf{8}]$. Recently there has been increased usage of resorbable screws and plates for trauma management [9]. The first account of internal fixation in treating maxillofacial fracture was with a brass wire in $1770[\mathbf{1 , 8}$, 10, 11]. Rigid internal fixation allowed immediate return to function and stable anatomic reduction [12]. Recently 3D miniplates have been considered due to their geometrical stability [13].

Recently miniplates has gained popularity as it satisfied four main goals: anatomical restitution, immobilization, prevention of infection and rehabilitation of function [14, 15]. A disadvantage of the conventional plate system is that it must be perfectly adapted to the underlying bone to avoid postoperative complications [16]. Stainless Steel and Titanium are the metals most commonly used for miniplates [16, 17]. A salient feature of locking plates is that it differentiates from conventional systems by not requiring very close adaptation with the underlying bone, making it easier for adaptation [16-18]. 
Although rigid internal fixation was used initially, miniplate osteosynthesis has become an important fixation method in trauma management often termed as "semi rigid" [19].

Stainless steel emerged as the new corrosion resistant miniplate material. At about the same time an alloy like titanium was introduced with claims of advantages over the classic stainless steel such as excellent corrosion resistance and biocompatibility as well as low modulus of elasticity (20). This study analyses the efficacy of miniplates in trauma management.

\section{MATERIALS AND METHOD}

This study was designed as a retrospective cross sectional study. All the patients with maxillofacial trauma who have been treated in the Department of Oral and Maxillofacial Surgery, Saveetha Dental College and Hospital, Chennai over a period of 10 months (1 June 2019 to 1 March 2020) were selected for the study.

A total of 89 patients were identified from the 89000 patient records that were analysed. Patients with Oral and Maxillofacial fracture, mandibular fracture and those who reported to the hospital within 7 days of trauma were included. Uncooperative and patients who were not willing to return for follow up were excluded from the study.
Casesheets that were duplicated and filled with incomplete information were eliminated with the verification of photographs and a total of 76 valid case sheets were identified, out of which 41 patients were operated with titanium miniplates and 35 patients with stainless steel miniplates. The study was reviewed by 2 reviewers and was cross verified. Data obtained were chronologically recorded and tabulated in the excel sheet.

The age, gender, material and number of miniplate used, along with the immediate review and outcome were further analyzed using Statistical Package for Social Sciences version 22 (SPSS). The results were tabulated based on frequencies and percentiles .Chi square test was used to detect the significance. $\mathrm{P}<0.005$ was considered statistically significant.

\section{RESULT AND DISCUSSION}

A total of 76 patients who have undergone trauma management were reviewed, of which 62 patients $(81.33 \%)$ showed satisfactory healing (31-titanium miniplates, 31-stainless steel miniplates) with no complications postoperatively in the immediate review and $14(18.67 \%)$ patients with moderate healing(10-titanium, 4- stainless steel) and certain complications who were advised for further review after 1 week. Among the population, the majority of the cases were in 
the age group 21-35 yrs with a mean age of 31.8 yrs. There were 66 males (86.30) and only 10 females $(13.7 \%)$ of Southeast asian origin. The most common cause for oral and maxillofacial trauma was road traffic accidents $(66,67 \%)$ followed by work related injury(20\%), self fall / Trauma (6.67\%) and other causes $(6.67 \%)$.
Fracture distribution consisted of 15 left condylar (20\%), 14 zygomaticomaxillary $(17.3 \%), 9$ right angle (12\%), 8 Bilateral parasymphysis $(10.7 \%), 7$ symphysis $(9.3 \%)$, 7 body of mandible (9.3\%), 6 right parasymphysis( $8 \%), 3$ left parasymphysis (4\%) and 3 right condyle (4\%) fractures, with a total of 10 fracture sites in the 76 cases selected.

Table 1: Shows the type of miniplate material used for the management of maxillofacial trauma with titanium miniplates $(53.3 \%)$ being the most common followed by stainless steel miniplates $(46.7 \%)$

\begin{tabular}{|c|c|c|}
\hline Miniplate material & Frequency (n) & Percentage (\%) \\
\hline Stainless steel & 36 & 46.7 \\
\hline Titanium & 40 & 53.3 \\
\hline Total & 76 & 100 \\
\hline
\end{tabular}

Table 2: Represents the number of miniplates used in trauma management with $2(39.5 \%)$ followed by $1(34.2 \%)$ and $3(26.3 \%)$. Majority of the miniplates used were 2 in number

\begin{tabular}{|c|c|c|}
\hline No of miniplates used & Frequency (n) & Percentage (\%) \\
\hline 1 & 26 & 34.2 \\
\hline 2 & 30 & 39.5 \\
\hline 3 & 20 & 26.3 \\
\hline
\end{tabular}

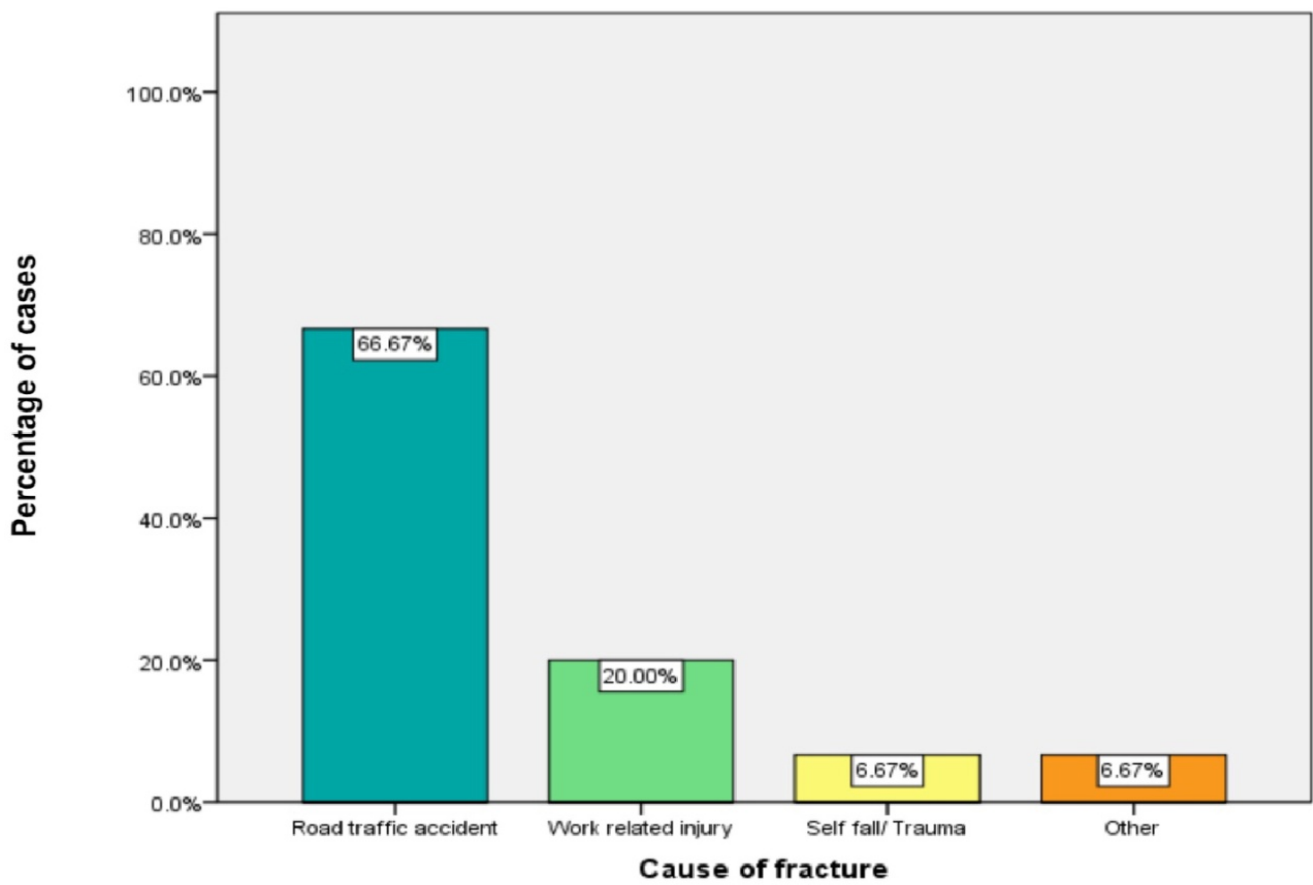

Figure 1: Depicts the cause of fracture of patients who reported to the hospital within 7 days of the incident. $X$ axis represents cause of fracture, $Y$ axis - the percentage of patients. Majority of the patients reported had road traffic accidents. 


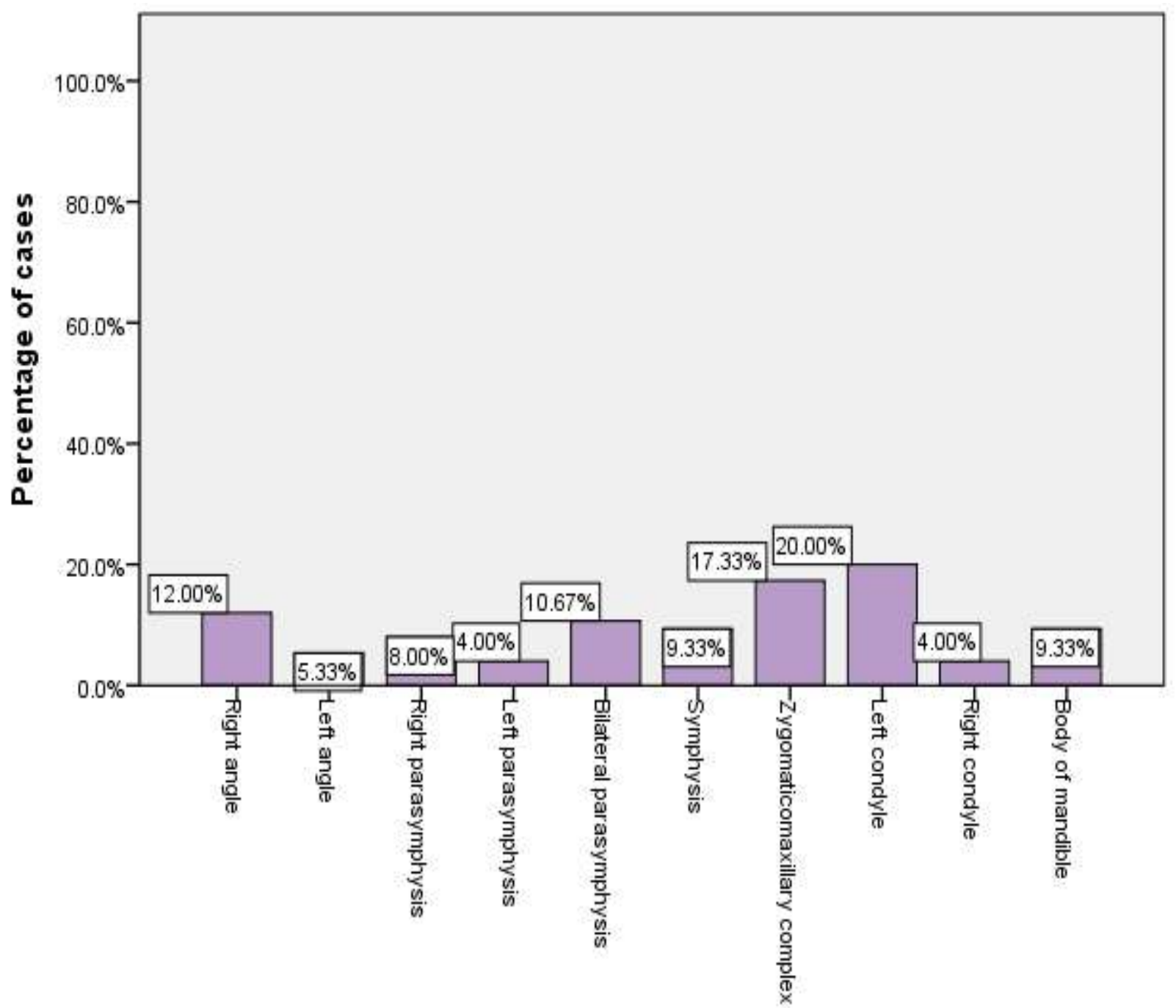

\section{Fracture site}

Figure 2: Graph shows the distribution of fracture based on the sites involved in the Maxillofacial region. $X$ axis represents the site of fracture $Y$ axis - the percentage.Condylar fractures are the most common site followed by Zygomaxillary complex. 


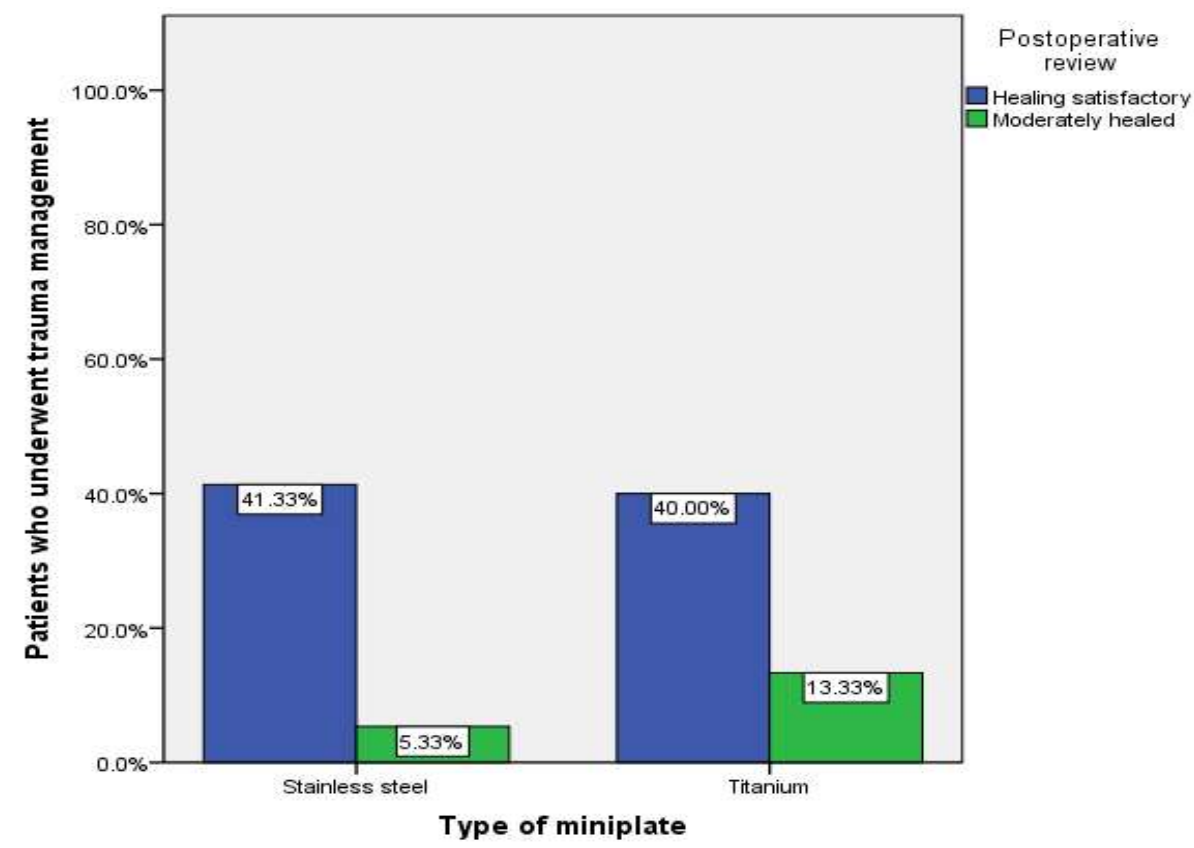

Figure 3 - Bar graph represents the association between miniplate used and postoperative review immediately the following day after surgery. $\mathrm{X}$ axis depicts the type of miniplate and $\mathrm{Y}$ axis depicts the percentage of patients who underwent trauma management. Titanium plates had more satisfactory bone healing compared to stainless steel plates.This was found to be statistically significant. Pearson Chi square test, $P$ value $=0.01$, where $\mathbf{p}<0.05$.

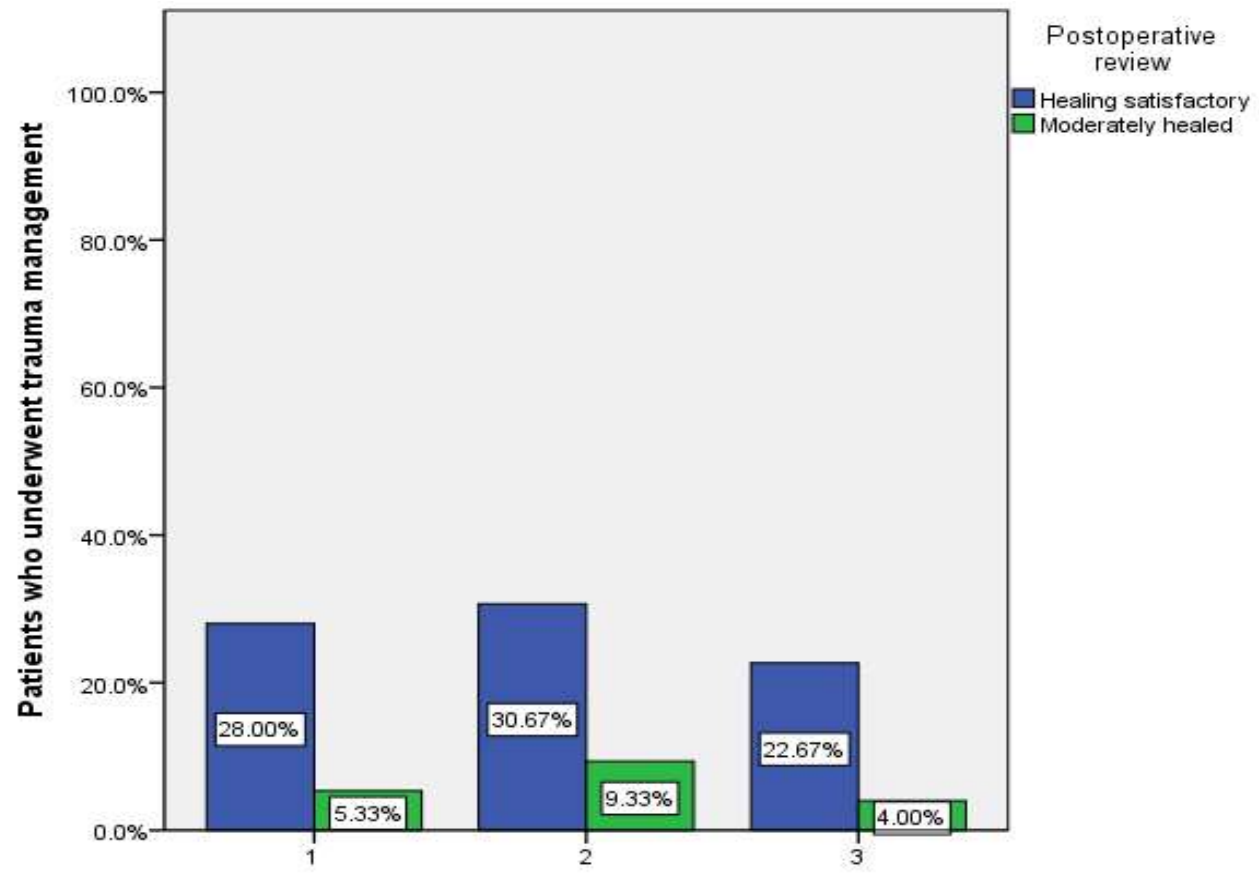

No. of miniplates used

Figure 4 - Bar graph represents the association between no of miniplate used and postoperative review immediately the following day after surgery. $X$ axis depicts the number of miniplates used and $Y$ axis depicts the percentage of patients . There was no significant difference in the number of miniplate used and bone healing. Pearson Chi square test, $P$ value $=$ 0.6, where $\mathbf{p}>0.05$ not significant implying that Healing period of bone is independent of the number miniplate used. 


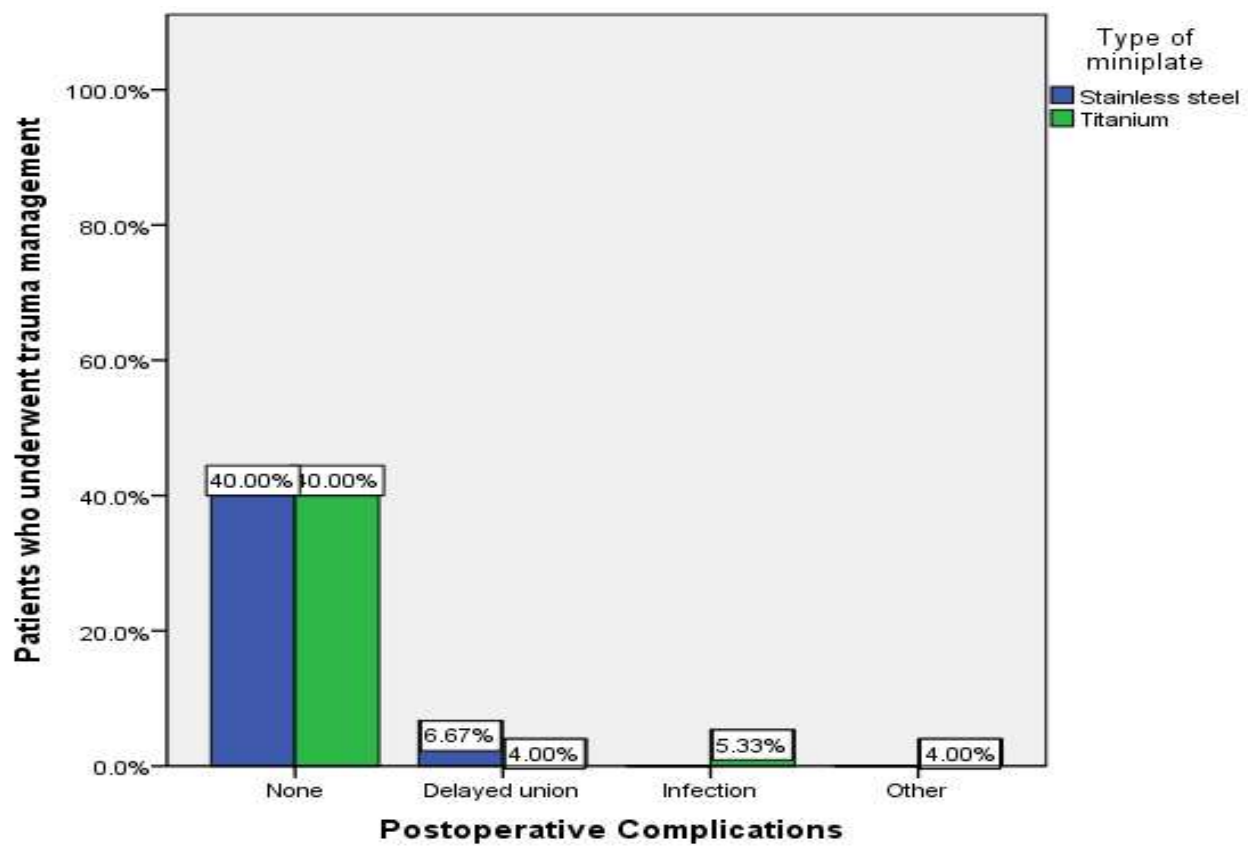

Figure 5- Graph shows the association of postoperative complications with the type of miniplates. $X$ axis depicts the postoperative complications and $Y$ axis depicts the percentage of patients who underwent trauma management There was no significant difference in the postoperative complications type of miniplate was done using Chi square test, $P$ value $=0.7$, where $\mathrm{p}>0.05$ implying that the type of miniplate does not influence development of postoperative complications

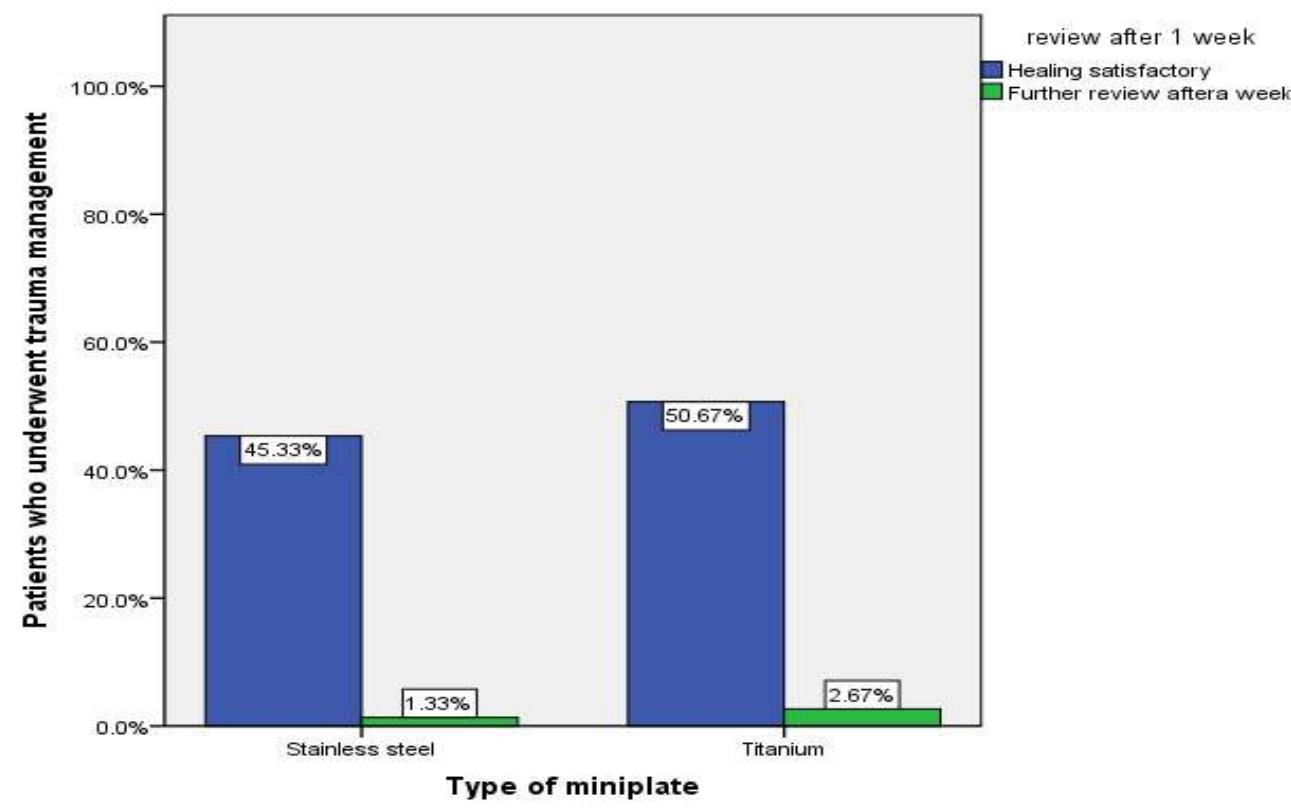

Figure 6 - Bar graph represents the association between type of miniplate and postoperative review after 1 week after surgery. $X$ axis depicts the type of miniplates and $Y$ axis depicts the percentage of patients who were reviewed 1 week after trauma management. Patients treated with titanium miniplates showed better results with satisfactory healing than those treated with stainless steel and it was found to be statistically significant.Chi square test, $P$ value $=0.01$, where $\mathbf{p}<\mathbf{0 . 0 5}$. 
Maxillofacial trauma is any physical trauma to the facial region, commonly encountered by maxillofacial surgeons, and is often associated with high morbidity [21, 22]. Even though implementation of strict traffic rules has been accomplished, the development of fast moving automobiles has contributed to higher incidence of road traffic accidents leading to maxillofacial traumas. Road traffic accident (66.67\%) was the most common cause of fracture in this study. Trauma management focuses on two main aspects, re establishing normal occlusion and masticatory function. Even after the initial treatment and trauma management, there are changes in facial profile, pattern and disfigurement in the maxillofacial skeleton. Besides road traffic accidents, heavy contact sports, violence and firearms are other etiological factors which are forms of direct or indirect trauma $[\mathbf{2 1}, \mathbf{2 3}]$.

In this study, $66(86.3 \%)$ of the study population were male while $10(13.7 \%)$ were females. This is so because, the males are more likely to engage in rash driving [24] under the influence of alcohol and disobey the traffic rules making them more susceptible to maxillofacial traumas while the females do not involve in drunk or rash driving and will likely be indoors. Previous studies by Ugboko et al and Qudah et al showed similar findings where men were more prevalent with higher frequency of jaw dislocation [21, 23, 25]. They discussed it as a consequence of high risk activities and drugs practiced by men [26]. The age of involvement peaked in the range of 21-35 years, in this study. This was authenticated by Chawasia et al, Ahmad et al and Kamulgaya whose conclusion states that the most affected age groups were 18-35 years of age. It could be the possibility of reduced physical movement in the young and older individuals that resulted in the lower frequency of trauma occurrence $[25,27]$.

Numerous fixation methods have been used for trauma management involving maxillofacial regions. The most popular system recently is the locking plate/ miniplate system as the important feature of the locking plate that differentiates it from conventional systems is the needless contact with the underlying bone, making it easier for adaptation making less chances of occurrence for alteration. These plates achieve stability by locking the screw into the plate and have been shown to enhance fixation stability [28]. This study revealed titanium as the most common type of miniplate material used for treatment followed by stainless steel. The modulus of elasticity of titanium is approximately half 
that of stainless steels and therefore create less risk of stress protection of bone. It also had excellent ductility and was totally nontoxic [29]. Stainless steel miniplates exhibit good stability whereas titanium plates exhibit high tensile strength, elasticity and are precisely adaptable. Shreya et al had similar findings in their study where stainless steel miniplates had a reasonable level of success. Both the miniplates show good mechanical properties by immediate stability $[28,30]$. However cost is an important factor and titanium miniplates are more expensive and stainless steel are more affordable. This could explain the results since the patients reporting in this hospital are mostly daily wagers and low income workers. The current study observed that the most common number of miniplates used was 2 . But there is no significance as the length as well as the number miniplates used could differ based on the site and type of fractures [31].

All of the cases were treated by open reduction by internal fixation where $81.33 \%(41.3 \%$-stainless steel and $40 \%$ titanium) showed successful outcome with satisfactory healing in the immediate review one day after surgery while $18.67 \%(5.3 \%$ stainless steel and $13.3 \%$-titanium) were moderately healed and were requested for further review either due to complications like infection or inadequate mouth opening or delayed union after a week or retreated due to postoperative complications. Postoperative complications were noted in seven patients. Four patients (5.3\%- titanium) developed an intraoral wound infection( which was treated with antibiotics and local measures and three had other minor complications like inadequate mouth opening and sensitivity (4\%-titanium) and were advised to follow physiotherapy instructions and medications. There was no major complication. Primary bone healing was noted in $80 \%$ of fracture sites and delayed union was observed in $10.7 \%$ (6.7\%-stainless steel and 4\%-titanium) of the patients with an overall postoperative complication of $9.3 \%$. Our study observations do correlate with those of the study conducted by Edward Ellis et al [32-34]. The bone healing at the fracture sites showed improvement in the review done one week after the surgery with $15 \%$ increase in satisfactory healing. The locking miniplate system was found to be effective and reliable in trauma management of maxillofacial fractures [32].

Even though titanium miniplates have achieved reliable results, they may require additional surgery for removal. Resorbable miniplates were developed to avoid this as they do not require subsequent removal and a 
second surgery is unnecessary [35]. Previous studies by Kallela et al and Wittwer et al reported similar biocompatibility characteristics with titanium miniplates. However findings by Bayram B et al were contractiditory where the results stated that resorbable plates do not provide satisfactory rigidity to counteract the masticatory forces eventually leading to delayed union compared to titanium based miniplates [36]. Further studies have to be conducted to evaluate the effectiveness of a resorbable miniplate in treatment of maxillofacial trauma.

\section{CONCLUSION}

The gravity of maxillofacial trauma is that they cause damage to the proximal cerebral and spinal anatomic structures leading life threatening complications. Therefore effective trauma management is essential. In conclusion, the present study has demonstrated the efficacy of miniplates in trauma management with sound bone healing and less postoperative complications.

Within the limits of the study, miniplates were found to be effective and remain a viable option in the treatment of maxillofacial fractures.

\section{REFERENCE}

[1] Moss M, Kruger GO, Reynolds DC. The effect of chondroitin sulfate on bone healing [Internet]. Vol. 20, Oral Surgery, Oral Medicine, Oral Pathology. 1965. p. 795-801. Available from:

http://dx.doi.org/10.1016/0030-

4220(65)90143-x

[2] Haug RH, Prather J, Indresano AT. An epidemiologic survey of facial fractures and concomitant injuries. $\mathrm{J}$ Oral Maxillofac Surg. 1990 Sep;48(9):926-32.

[3] Christabel A, Anantanarayanan P, Subash P, Soh CL, Ramanathan M, Muthusekhar MR, et al. Comparison of pterygomaxillary dysjunction with tuberosity separation in isolated Le Fort I osteotomies: a prospective, multi-centre, triple-blind, randomized controlled trial [Internet]. Vol. 45, International Journal of Oral and Maxillofacial Surgery. 2016. p. 1805. Available from: http://dx.doi.org/10.1016/j.ijom.2015. 07.021

[4] Abdullah WA, Al-Mutairi K, Al-Ali Y, Al-Soghier A, Al-Shnwani A. Patterns and etiology of maxillofacial fractures in Riyadh City, Saudi Arabia [Internet]. Vol. 25, The Saudi Dental Journal. 2013. p. 33-8. Available from: 
http://dx.doi.org/10.1016/j.sdentj.201

2.10 .004

[5] Down KE, Boot DA, Gorman DF. Maxillofacial and associated injuries in severely traumatized patients: implications of a regional survey [Internet]. Vol. 24, International Journal of Oral and Maxillofacial Surgery. 1995. p. 409-12. Available from:

http://dx.doi.org/10.1016/s09015027(05)80469-2

[6] Kumar S, Rahman R. Knowledge, Awareness, And Practices Regarding Biomedical Waste Management Among Undergraduate Dental Students [Internet]. Vol. 10, Asian Journal of Pharmaceutical and Clinical Research. 2017. p. 341. Available from: http://dx.doi.org/10.22159/ajpcr.2017. v10i8.19101

[7] Brasileiro BF, Passeri LA. Epidemiological analysis of maxillofacial fractures in Brazil: A 5year prospective study [Internet]. Vol. 102, Oral Surgery, Oral Medicine, Oral Pathology, Oral Radiology, and Endodontology. 2006. p. 28-34. Available from: http://dx.doi.org/10.1016/j.tripleo.200

\subsection{7 .023}

[8] Smolka W, Liokatis P, Cornelius C-P. Evaluation of Complications After Open Reduction and Internal Fixation of Mandibular Condylar Base and Neck Fractures Using Trapezoidal Plates. J Craniofac Surg [Internet]. 2020 May 4; Available from: http://dx.doi.org/10.1097/SCS.00000 00000006486

[9] Kumar S. Knowledge, Attitude And Awareness Of Dental Undergraduate Students Regarding Hiv/Aids Patients [Internet]. Vol. 10, Asian Journal of Pharmaceutical and Clinical Research. 2017. p. 175. Available from:

http://dx.doi.org/10.22159/ajpcr.2017. v10i5.17277

[10] Fonseca RJ. Oral and Maxillofacial Surgery - E-Book: 3-Volume Set. Elsevier Health Sciences; 2017. $2696 \mathrm{p}$.

[11] Abhinav RP, Sweta VR, Ramesh A. Role of virtual reality in pain perception of patients following the administration of local anesthesia [Internet]. Vol. 9, Annals of Maxillofacial Surgery. 2019. p. 110. Available from: http://dx.doi.org/10.4103/ams.ams 
$263+18$

[12] Iizuka $T$, Lindqvist $C$, Hallikainen D, Paukku P. Infection after rigid internal fixation of mandibular fractures: A clinical and radiologic study [Internet]. Vol. 49, Journal of Oral and Maxillofacial Surgery. 1991. p. 585-93. Available from: http://dx.doi.org/10.1016/02782391(91)90340-r

[13] Prasad R, John R, Thangavelu K. The role of $3 \mathrm{D}$ plating system in mandibular fractures: A prospective study [Internet]. Vol. 5, Journal of Pharmacy and Bioallied Sciences. 2013. p. 10. Available from: http://dx.doi.org/10.4103/09757406.113280

[14] Peled M, Laufer D, Helman J, Gutman D. Treatment of mandibular fractures by means of compression osteosynthesis [Internet]. Vol. 47, Journal of Oral and Maxillofacial Surgery. 1989. p. 566-9. Available from:

http://dx.doi.org/10.1016/s02782391(89)80068-0

[15] Patturaja K, Pradeep D. Awareness of Basic Dental Procedure among General Population [Internet]. Vol. 9, Research Journal of Pharmacy and Technology. 2016. p. 1349. Available from: http://dx.doi.org/10.5958/0974360x.2016.00258.4

[16] Alpert B, Gutwald R, Schmelzeisen R. New innovations in craniomaxillofacial fixation: the 2.0 lock system [Internet]. Vol. 52, The Keio Journal of Medicine. 2003. p. 120-7. Available from: http://dx.doi.org/10.2302/kjm.52.12 0

[17] Jimson S, Sankar A, Prasad R. Comparative study of stainless steel miniplate, three-dimensional plate and titanium three-dimensional plate for fixation of mandibular fractures [Internet]. Vol. 38, International Journal of Oral and Maxillofacial Surgery. 2009. p. 502-3. Available from:

http://dx.doi.org/10.1016/j.ijom.200 9.03.380

[18] Chuong R, Bruce Donoff R, Guralnick WC. A retrospective analysis of 327 mandibular fractures [Internet]. Vol. 41, Journal of Oral and Maxillofacial Surgery. 1983. p. 305-9. Available from: http://dx.doi.org/10.1016/02782391(83)90297-5 
[19] Mittal G, Dubbudu RR, Cariappa KM. Three Dimensional Titanium Mini Plates in Oral \& Maxillofacial Surgery: A Prospective Clinical Trial [Internet]. Vol. 11, Journal of Maxillofacial and Oral Surgery. 2012. p. 152-9. Available from: http://dx.doi.org/10.1007/s12663011-0267-0

[20] Vyas A, Mazumdar U, Khan F, Mehra M, Parihar L, Purohit C. A study of mandibular fractures over a 5-year period of time: A retrospective study [Internet]. Vol. 5, Contemporary Clinical Dentistry. 2014. p. 452. Available from: http://dx.doi.org/10.4103/0976$237 \mathrm{x} .142808$

[21] Leles JLR, dos Santos ÊJ, Jorge FD, da Silva ET, Leles CR. Risk factors for maxillofacial injuries in a Brazilian emergency hospital sample [Internet]. Vol. 18, Journal of Applied Oral Science. 2010. p. 23-9. Available from: http://dx.doi.org/10.1590/s167877572010000100006

[22] Abhinav RP, Selvarasu K, Maheswari GU, Taltia AA. The Patterns and Etiology of Maxillofacial Trauma in South
India. Ann Maxillofac Surg. 2019 Jan;9(1):114-7.

[23] Zaleckas L, Drobnys P, Rimkuvienè J. Incidence and etiology of mandibular fractures treated in Vilnius University Hospital Žalgiris clinic, Lithuania: a review of 1508 cases [Internet]. Vol. 20, Acta medica Lituanica. 2013. Available from:

http://dx.doi.org/10.6001/actamedic a.v20i1.2627

[24] Kumar S. Relationship Between Dental Anxiety And Pain Experience During Dental Extractions [Internet]. Vol. 10, Asian Journal of Pharmaceutical and Clinical Research. 2017. p. 458. Available from: http://dx.doi.org/10.22159/ajpcr.201 7.v10i3.16518

[25] Bataineh AB. Etiology and incidence of maxillofacial fractures in the north of Jordan. Oral Surg Oral Med Oral Pathol Oral Radiol Endod. 1998 Jul;86(1):31-5.

[26] Qudah MA, Al-Khateeb T, Bataineh AB, Rawashdeh MA. Mandibular fractures in Jordanians: a comparative study between young and adult patients. J 
Craniomaxillofac Surg. 2005 Apr;33(2):103-6.

[27] Ugboko VI, Odusanya SA, Fagade OO. Maxillofacial fractures in a semi-urban Nigerian teaching hospital. A review of 442 cases. Int J Oral Maxillofac Surg. 1998 Aug;27(4):286-9.

[28] Prabhakar C, Shetty JN, Hemavathy OR, Guruprasad Y. Efficacy of 2$\mathrm{mm}$ locking miniplates in the management of mandibular fractures without maxillomandibular fixation. Natl J Maxillofac Surg. 2011 Jan;2(1):28-32.

[29] Torgersen S, Moe G, Jonsson R. Immunocompetent cells adjacent to stainless steel and titanium miniplates and screws [Internet]. Vol. 103, European Journal of Oral Sciences. 1995. p. 46-54. Available from:

http://dx.doi.org/10.1111/j.1600-

0722.1995.tb00010.x

[30] Gussack GS. Rowe and Williams' maxillofacial injuries, second edition. J. Ll. Williams, Churchill Livingstone, New York, 1994, 1,087 pp, \$295.00 [Internet]. Vol. 17, Head \& Neck. 1995. p. 552-3. Available from: http://dx.doi.org/10.1002/hed.28801 70617

[31] Bolourian R, Lazow S, Berger J. Transoral 2.0-mm miniplate fixation of mandibular fractures plus 2 weeks' maxillomandibular fixation: A prospective study [Internet]. Vol. 60, Journal of Oral and Maxillofacial Surgery. 2002. p. 167-70. Available from: http://dx.doi.org/10.1053/joms.2002. 29813

[32] Chritah A, Lazow SK, Berger JR. Transoral 2.0-mm Locking Miniplate Fixation of Mandibular Fractures Plus 1 Week of Maxillomandibular Fixation: A Prospective Study [Internet]. Vol. 63, Journal of Oral and Maxillofacial Surgery. 2005. p. 1737-41. Available from: http://dx.doi.org/10.1016/j.joms.200 5.08 .022

[33] Jesudasan JS, Abdul Wahab PU, Muthu Sekhar MR. Effectiveness of $0.2 \%$ chlorhexidine gel and a eugenol-based paste on postoperative alveolar osteitis in patients having third molars extracted: a randomised controlled clinical trial [Internet]. Vol. 53, 
British Journal of Oral and

Maxillofacial Surgery. 2015. p.

826-30. Available from:

http://dx.doi.org/10.1016/j.bjoms.20

15.06 .022

[34] Ellis E, Graham J. Use of a 2.0-mm locking plate/screw system for mandibular fracture surgery [Internet]. Vol. 60, Journal of Oral and Maxillofacial Surgery. 2002. p. 642-5. Available from: http://dx.doi.org/10.1053/joms.2002. 33110

[35] Ketola T, Laine P, Lindqvist C, Suuronen R. Bioabsorbable plates and screws in the fixation of mandibular fractures [Internet]. Vol. 34 , International Journal of Oral and Maxillofacial Surgery. 2005. p. 158. Available from: http://dx.doi.org/10.1016/s09015027(05)81512-7

[36] Bayram B, Araz K, Uckan S, Balcik C. Comparison of Fixation Stability of Resorbable Versus Titanium Plate and Screws in Mandibular Angle Fractures [Internet]. Vol. 67, Journal of Oral and Maxillofacial Surgery. 2009. p. 1644-8. Available from:

http://dx.doi.org/10.1016/j.joms.200 